\title{
The acute effect of aquatic physiotherapy on heart rate, blood pressure, and double product in individuals with Parkinson's disease
}

\author{
DOI: https://doi.org/10.5114/pq.2021.105756
}

\author{
Juliana Siega, Adriano Zanardi da Silva, Manoela de Paula Ferreira, Bruna Yamaguchi, Vera Lucia Israel \\ Physical Education Department, Federal University of Paraná, Curitiba, Brazil
}

\begin{abstract}
Introduction. This study investigated changes in blood pressure, heart rate, and double product in patients with Parkinson's disease who participated in aquatic physiotherapy.

Methods. A single group research design was applied. Overall, 20 sessions of aquatic physiotherapy were implemented, 2 times per week, each lasting for 40 minutes. Heart rate and blood pressure were measured before and after each session. Overall, 13 participants in stages 2-4 on the Hoehn and Yahr scale were assessed.

Results. Statistically significant differences were observed for the final heart rate $(p=0.001)$, final double product $(p=0.001)$, and diastolic blood pressure $(p=0.03)$

Conclusions. We had observed an increase in the means of the heart rate, double product, and diastolic blood pressure in people with Parkinson's disease.

Key words: Parkinson's disease, hydrotherapy, blood pressure, heart rate, exercise, rehabilitation
\end{abstract}

\section{Introduction}

Cardiopulmonary conditions are considered to be among the main causes of death in individuals with advanced neurodegenerative diseases. This is due to changes in the expansion of the chest, which reduce the pulmonary volume and restrict ventilation, consequently contributing to a decrease in respiratory function [1]. Parkinson's disease (PD) is one of these chronic, degenerative, and progressive diseases of the central nervous system; it causes the death of dopaminergic neurons present in the substantia nigra. This decrease in dopaminergic neurons results in motor disorders and postural, cognitive, and respiratory dysfunction [2].

Aquatic physiotherapy (AP) is a promising therapy option that can target different PD symptoms, including cardiopulmonary function. Several studies [3-5] have revealed that AP is beneficial for people with PD owing to the immersion of the body in warm water. In addition, these studies highlighted the positive effect of AP on physical and cardiopulmonary conditioning, muscle relaxation, muscle strength and stiffness, and blood flow. Various physiological changes occur as a result of exercise in water compared with those on land. Cardiac output is approximately $25 \%$ higher when in water. Furthermore, heart rate increases in response to the rising temperatures and exercise in water [6].

While heart rate and blood pressure are commonly reported measures of cardiovascular changes during exercise, the double product is considered to be a more reliable and more accurate reflection of how the heart works during continuous physical effort. The double product - which is the systolic blood pressure multiplied by heart rate - has an increased reliability owing to the association between heart rate and systolic blood pressure, exposing oxygen consumption and the impact of effort on the myocardium [6]. Because of the way it is calculated, the double product tends to be low in resistance exercises and high (up to 5 times higher) in aerobic and water exercises. This is explained by the lower peak heart rate during resistance exercises. Conversely, high double product values during exercise are synonymous with heart rate, systolic volume, cardiac output, and systemic resistance increases [7]. The double product is an indirect predictor of effort and is also assumed as a parameter for safety in the prescription of exercise, especially in vulnerable populations [8].

In healthy individuals, blood pressure and heart rate tend to increase while performing physical exercises and increasing their intensity. However, in patients with PD, this response is not normal since they exhibit a decrease in heart rate response and variation in cardiac reflexes [9]. Such changes and responses to physical exercise still constitute a gap in the current literature. Accordingly, the objective of this study was to analyse the acute modifications of heart rate, blood pressure, and double product measured before and after AP in individuals with PD.

\section{Subjects and methods}

A single group research design was applied in the study. The patients' individual outcomes were compared before/ after the intervention program and before/after each session.

The participants were selected from the Brazilian Association of Patients with Parkinsonism through verbal invitation, owing to the convenience of the researchers. The research lasted from January to July 2016. The study included individuals of both sexes with a clinical diagnosis of PD in stages 1-4 on the Hoehn and Yahr scale. All participants had clinical certificates allowing physical activity in the water and authorization to attend a heated pool. The exclusion criteria considered in the study were: (a) absence of independent walking; (b) cognitive, visual, or hearing deficits,

Correspondence address: Juliana Siega, Physical Education Department, Federal University of Paraná, Coração de Maria, 92. Curitiba-Paraná, Brazil, e-mail: jusiega@hotmail.com 
since these would make the adherence to verbal/visual instructions difficult, thus resulting in a contraindication for attending a heated swimming pool; (c) change in PD prescription medication during the intervention period.

The variables measured for analysis were heart rate and blood pressure. The heart rate was evaluated via the pulse of the radial artery over a 1-minute period. For the assessment of blood pressure, a stethoscope and properly calibrated sphygmomanometer were used. All measurements were taken approximately 5-10 minutes before and after the AP sessions.

In total, 20 AP sessions were completed, 2 times per week, each lasting for 40 minutes. All measurements were performed by the same physiotherapist, who was properly trained and adhered to the measurement periods stipulated, before and after AP. The sessions consisted of 40 minutes of immersion, with dual-task aquatic exercises involving aquatic motor skills, progressing from the achievement of the skill from the previous task. The intervention is described in full detail in our previous study [10] and was controlled by the data on the vital signs measured before and after immersion.

Data normality was assessed by using the Shapiro-Wilk test. As the data did not follow a normal distribution, the comparison of the status before and after AP was made with the Wilcoxon test.

\section{Ethical approval}

The research related to human use has complied with all the relevant national regulations and institutional policies, has followed the tenets of the Declaration of Helsinki, has been approved by the Committee of Ethics in Research of the Hospital do Trabalhador, under the approval number 05271512.7.00005225, and is related to the study stored in the Brazilian Clinical Trials Registry under the number RBR8cxzf2.

\section{Informed consent}

Informed consent has been obtained from all individuals included in this study.

\section{Results}

A total of 13 participants were evaluated, with a mean age of $64 \pm 11.78$ years. Of those, 5 subjects were males and 8 were females. They suffered from PD in stages 2-4 of the Hoehn and Yahr scale, with independent walking and cognitive status preserved.

Table 1 presents the values of pre- and post-immersion heart rate. An increase in mean heart rate was observed after AP.

Table 2 depicts the values of the diastolic blood pressure before and after immersion. An increase in the mean blood pressure of all participants after AP was observed at the $75^{\text {th }}$ percentile.

Table 3 shows the values of pre- and post-immersion systolic blood pressure. One can observe that there was no change in this variable as a result of AP.

Table 4 presents the values of the pre- and post-immersion double product. A higher mean double product was observed in all participants in the post-immersion period.

The variables that exhibited a significant difference between the pre- and post-immersion period were final heart rate $(p=0.001)$, final diastolic blood pressure $(p=0.03)$, and final double product $(p=0.001)$.
Table 1. Pre- and post-immersion mean heart rate

\begin{tabular}{|l|c|c|c|}
\hline \multirow{2}{*}{ Pondered average } & \multicolumn{3}{|c|}{ Percentiles } \\
\cline { 2 - 4 } & 25 & 50 & 75 \\
\hline Heart rate - initial (bpm) & 72 & 78 & 84 \\
\hline Heart rate - final (bpm) & 76 & 80 & 88 \\
\hline
\end{tabular}

Table 2. Mean diastolic blood pressure before and after immersion

\begin{tabular}{|l|c|c|c|}
\hline \multirow{2}{*}{$\begin{array}{l}\text { Pondered average } \\
\text { (first assessment) }\end{array}$} & \multicolumn{3}{|c|}{ Percentiles } \\
\cline { 2 - 4 } & 25 & 50 & 75 \\
\hline Blood pressure - initial $(\mathrm{mm} \mathrm{Hg})$ & 70 & 80 & 80 \\
\hline Blood pressure - final $(\mathrm{mm} \mathrm{Hg})$ & 70 & 80 & 90 \\
\hline
\end{tabular}

Table 3. Mean pre- and post-immersion systolic blood pressure

\begin{tabular}{|l|c|c|c|}
\hline \multirow{2}{*}{$\begin{array}{l}\text { Pondered average } \\
\text { (last assessment) }\end{array}$} & \multicolumn{3}{|c|}{ Percentiles } \\
\cline { 2 - 4 } & 25 & 50 & 75 \\
\hline Blood pressure - initial $(\mathrm{mm} \mathrm{Hg})$ & 110 & 120 & 130 \\
\hline Blood pressure - final $(\mathrm{mm} \mathrm{Hg})$ & 110 & 120 & 130 \\
\hline
\end{tabular}

Table 4. Mean pre- and post-immersion double product

\begin{tabular}{|l|c|c|c|}
\hline \multirow{2}{*}{ Pondered average } & \multicolumn{3}{|c|}{ Percentiles } \\
\cline { 2 - 4 } & 25 & 50 & 75 \\
\hline Double product - initial & 8400 & 9240 & 10,140 \\
\hline Double product - final & 8880 & 9600 & 10,780 \\
\hline
\end{tabular}

\section{Discussion}

It was observed that immersion in heated water and therapeutic exercises increased mean heart rate, diastolic blood pressure, and the double product, while keeping the values within a safe range for exercise.

Other studies that analysed heart rate and blood pressure changes after immersion periods found similar responses. Candeloro and Caromano [11], in a study performed among sedentary elderly women, investigated changes in blood pressure and heart rate measured 3 minutes after leaving the pool after a hydrotherapy session. Guimarães et al. [12] also analysed these responses in a group of patients aged 50-60 years admitted to the University of São Paulo hospital who underwent hydrotherapy sessions. Both studies showed an increase in the diastolic blood pressure and heart rate of the patients after the immersion exercise.

In a different population, consisting of stroke individuals, it was observed that physical exercise inside the water - in this case, walking exercise - reduced blood pressure (both systolic and diastolic) in comparison with the same exercise performed outside the water. The participants did not present changes in heart rate, which suggests that aquatic exercise may be a safer option since it does not overload the cardiovascular system [13, 14].

Changes resulting from immersion, such as vasoconstriction associated with sodium reabsorption, inhibition of sympathetic activity, and suppression of the renin-angiotensin-aldosterone system, together with the practice of physical exercises, are indicated as sufficient factors for an increase of heart rate and blood pressure in patients participating in 
AP $[11,12]$. Conversely, the return to land and the elimination of the aquatic factors, such as hydrostatic pressure, dissipates the venous return facilitator, resulting in ground situations bearing greater vascular stress. This also influences the increased heart rate during AP [15], which in turn causes the person to adjust in order to remain in hemodynamic equilibrium.

The normalization of double product values considers variables such as age, sex, body mass index, and physical activity level. The values are classified in 3 categories: double product at rest (values of $7524 \pm 1753$ ), double product during submaximal exercise (values of $21,218 \pm 8928$ ), and double product during maximum exercise (values of 32,798 $\pm 446,514$ ) [14]. Assuming that the proposed activities during the AP sessions aimed to achieve a moderate intensity for the patients, the double product values from our study presented results between resting values and those obtained during submaximal exercise testing. Thus, it can be concluded that the proposed exercises prescribed to the PD population were within a range that would allow for safe practice. Chronically, the practice of physical exercises increases the $\mathrm{VO}_{2}$ max of the muscles, and the muscles raise their capacity to capture, transport, and use oxygen [16]; furthermore, resting heart rate can also be reduced [17]. Consequently, the cardiac effort tends to decrease. This is one of the reasons why physical exercise is considered cardioprotective [16], even in patients with chronic degenerative disease, as was observed in this study, which highlights the importance of being physically active, despite pervasive health conditions, and emphasizes the self-efficacy of exercises $[18,19]$.

Long-term effects are also evident in heart rate and blood pressure; owing to hemodynamic changes in blood volume and venous tone, a reduction in heart rate and blood pressure may occur $[20,21]$. This reduction, accompanied by a decrease in cardiac output and the sympathetic tone in the heart, causes less sympathetic intensification and greater vagal withdrawal [22]. Catecholamine levels that vary depending on the function of exercises in the aquatic environment also reflect a reduction in heart rate [5].

Thus, the increased values of post-immersion heart rate and diastolic blood pressure reflect the expected and correlated physiological cardiovascular response to the immersion associated with physical exercise, which may indicate positive effects of AP in improving blood pumping capacity. In turn, the increase in the double product, while still remaining within the expected range, allowed for the intensity of the exercises proposed in the intervention to be classified as safe for the studied population, composed of people with PD, predominantly advanced in age.

\section{Limitations}

As limitations of the study, we highlight the lack of a control group to compare the variables analysed. It is also suggested to include individuals in the initial stage of PD (stage 1 of the Hoehn and Yahr scale) in further research.

\section{Conclusions}

The immersion period associated with the proposed level of exercises may have been responsible for the expected changes in heart rate, diastolic blood pressure, and double product. These changes may also have occurred as a physiological response to the exercise in the aquatic environment, which has proved to be adequate and safe for this kind of practice. This was an investigation of the acute effect of AP on cardiopulmonary variables. It is expected, from the observations of this and other research, that the response is chronic in its character.

\section{Acknowledgements}

This study was funded in part by the Coordenação de Aperfeiçoamento de Pessoal de Nível Superior (CAPES), Brazil (Finance Code 001).

The authors would like to thank the Pontificia Universidad Católica for yielding the heated swimming pool and the Academic Publishing Advisory Centre (Centro de Assessoria de Publicação Acadêmica) of the Federal University of Paraná for assistance with English language editing.

\section{Disclosure statement}

No author has any financial interest or received any financial benefit from this research.

\section{Conflict of interest}

The authors state no conflict of interest.

\section{References}

1. Ferreira FV, Cielo CA, Trevisan ME. Respiratory muscle strength, body posture, vocal intensity and maximum phonation times in Parkinson disease [in Portuguese]. Rev CEFAC. 2012;14(2):361-368; doi: 10.1590/S151618462010005000135.

2. Peternella FMN, Marcon SS. Diagnosed with Parkinson's disease: impact on patients and family members [in Portuguese]. Rev Bras Enferm. 2009;62(1):25-31; doi: 10.1590/s0034-71672009000100004.

3. Fernandes Â, Coelho T, Vitória A, Ferreira A, Santos R, Rocha N, et al. Standing balance in individuals with Parkinson's disease during single and dual-task conditions. Gait Posture. 2015;42(3):323-328; doi: 10.1016/j.gaitpost.2015.06.188.

4. Haase DCBV, Machado DC, Oliveira JGD. The physiotherapy's performance in the patient with illness of Parkinson [in Portuguese]. Fisioter Mov. 2008;21(1):79-85.

5. Kanitz AC, Delevatti RS, Reichert T, Liedtke GV, Ferrari $\mathrm{R}$, Almada $\mathrm{BP}$, et al. Effects of two deep water training programs on cardiorespiratory and muscular strength responses in older adults. Exp Gerontol. 2015;64:55-61; doi: 10.1016/j.exger.2015.02.013.

6. Pereira JAG, Lima JPS, Oliveira MM. Comparative study of heart rate and blood pressure before and after aerobic exercise on land and in water in elderly people of the "active life in old age" project [in Portuguese]. Course graduation work. Pará: Universidade da Amazônia; 2007.

7. Lopes LTP, Gonçalves A, Resende ES. Double product response and diastolic blood pressure in treadmill, stationary bicycle and muscular circuit exercises [in Portuguese]. Rev Bras Cineantropom Desempenho Hum. 2006;8(2):53-58.

8. Farinatti PTV, Assis BFCB. Heart rate, arterial blood pressure and double-product during resistance dynamic and aerobic exercises [in Portuguese]. Rev Bras Ativ Fís Saúde. 2000;5(2):5-16; doi: 10.12820/rbafs.v.5n2p5-16.

9. Bryant MS, Jackson GR, Hou JG, Protas EJ. Treadmill exercise tests in persons with Parkinson's disease: responses and disease severity. Aging Clin Exp Res. 2015; 28(5):1009-1014; doi: 10.1007/s40520-015-0498-x.

10. Da Silva AZ, Israel VL. Effects of dual-task aquatic exercises on functional mobility, balance and gait of individuals with Parkinson's disease: a randomized clinical trial with a 3-month follow-up. Complement Ther Med. 2019;42(1):119-124; doi: 10.1016/j.ctim.2018.10.023. 
11. Candeloro JM, Caromano FA. Effects of a hidrotherapy program on blood pressure and heart rate in elderly, sedentary women [in Portuguese]. Fisioter Pesqui. 2008; 15(1):26-32; doi: 10.1590/S1809-29502008000100005.

12. Guimarães GV, Cruz LGB, Tavares AC, Dorea EL, Fernandes-Silva MM, Bocchi EA. Effects of short-term heated water-based exercise training on systemic blood pressure in patients with resistant hypertension: a pilot study. Blood Press Monit. 2013;18(6):342-345; doi: 10.1097/ MBP.0000000000000000.

13. Yoo J, Lim K-B, Lee H-J, Kwon Y-G. Cardiovascular response during submaximal underwater treadmill exercise in stroke patients. Ann Rehabil Med. 2014;38(5): 628-636; doi: 10.5535/arm.2014.38.5.628.

14. Kabuki MT, de Sá TS. The effect of hydrotherapy in high blood pressure and heart rate in patients with stroke [in Portuguese]. Rev Neurocienc. 2007;15(2):131-134; doi: 10.34024/rnc.2007.v15.10292.

15. Hui SC, Jackson AS, Wier LT. Development of normative values for resting and exercise rate pressure product. Med Sci Sports Exerc. 2000;32(8):1520-1527; doi: 10.1097/00005768-200008000-00023.

16. Ramires FJA, Fernandes F, Dantas S. The myocardium in obesity [in Portuguese]. Rev Soc Cardiol. 2003;13(4): 399-403.

17. De Brito-Gomes JL, dos Santos Oliveira L, Araujo de Souza A, de Freitas Brito A, Cavalcante Figueredo do Monte $\mathrm{R}$, da Cunha Costa M. Does a virtual functional training induce cardiovascular responses in normotensive adults after a single session and over weeks? Hum Mov. 2019;20(2):25-33; doi: 10.5114/hm.2019.79732.

18. Ogwumike OO, Musa SB. Relationships among walking speed, selected clinical symptoms, and exercise selfefficacy in individuals with knee osteoarthritis. Hum Mov. 2019;20(2):79-84; doi: 10.5114/hm.2019.81023.

19. Siega J, lucksch DD, Alves MAR, Heeren CES, Israel VL. Elderly practitioners of water exercises: a biopsychosocial view with international classification of functionality (ICF) [in Portuguese]. R Bras Qual Vida. 2020;12(2): e10989; doi: 10.3895/rbqv.v12n2.10989.

20. Caromano FA, Themudo Filho MRF, Monteiro Candeloro J. Physiological effects of immersion and the practice of exercise in the water [in Portuguese]. Fisioter Bras. 2003;4(1):61-66; doi: 10.33233/fb.v4i1.3001.

21. Vivacqua R, Serra S, Macaciel R, Miranda M, Bueno N, Campos A. Stress test in the elderly. Clinical, hemodynamic, metabolic and electrocardiographic variables [in Portuguese]. Arq Bras Cardiol. 1997;68(1):9-12.

22. Gimenes RO, Carvalho NTP, Farelli BC, Mello TWP. Impact of aquatic physiotherapy on arterial pressure of aged people [in Portuguese]. Mundo Saúde. 2008;32(2): $170-175$. 